\title{
Where is the Family in Young Adult Substance Use Treatment? The Case for Systemic Family Therapy for Young Adults with Substance Use Disorders
}

\author{
Rachel R. Tambling ${ }^{1}$ (D) $\cdot$ Beth Russell ${ }^{1} \cdot$ Carissa D'Aniello ${ }^{2}$
}

Accepted: 15 December 2020 /Published online: 4 January 2021

(C) The Author(s), under exclusive licence to Springer Science+Business Media, LLC part of Springer Nature 2021

\begin{abstract}
Despite the prevalence of SUDs, many individuals remain untreated (Grant et al., JAMA Psychiatry, 73(1), 39-45, 2016). Substance use disorders (SUDs) in young adults present unique challenges and stressors to parents of these individuals (D'Aniello et al., American Journal of Family Therapy, 2020; Kaur et al., International Journal of Community Medicine and Public Health, 5(6), 2380-2383, 2018; Shumway et al., Alcoholism Treatment Quarterly, 37(1), 75-98, 2019). Parents and caregivers often facilitate their children's care and provide pragmatic and emotional support to their children; this high level of care is challenging to maintain, as with any chronic, relapsing condition. In the case of SUDs, the challenges caregivers face may be exacerbated by the stigma and the blame associated with parents in the development and maintenance of children's SUDs, and the strains that come with navigating barriers related to accessing treatment in the USA. Estimates suggest that healthcare spending for substance use treatment is relatively low and few utilize therapeutic family treatment. This disconnect between widespread SUD prevalence, and service underutilization, indicates that families who need treatment are not accessing it. The present paper synthesizes the extant literature on the role of family members in SUD treatment, as families are a primary context of care for their children's treatment across many chronic, relapsing conditions. Finally, we identify the utility of family therapy in addressing family member's unique needs related to their loved one with a SUD, in the family and in a treatment context.
\end{abstract}

Keywords Substance use disorders · Treatment · Caregivers · Family therapy

Rachel R. Tambling

Rachel.Tambling@uconn.edu

1 Department of Human Development and Family Sciences, University of Connecticut, 348 Mansfield Rd., U-1058, Storrs, CT 06269-1058, USA

2 Community, Family, and Addiction Services, Texas Tech University, 2500 Broadway, Lubbock, TX 79409, USA 
Caregivers, including parents, grandparents, family members, and family of choice, hold a critical role in shaping youth behavior through their parenting practices, and their emotional relationships (Smokowski et al. 2018). Positive caregiver-child relationships that include warmth, cohesion, and support can serve as a critical protective factor from engagement in problematic behavior (Gorman-Smith et al. 2000; Smokowski et al. 2018). We assert that the importance of the caregiver-child relationship extends through adolescence and remains salient into young adulthood. Research has shown that substance use disorders (SUDs) in young adults present unique challenges and stressors to parents of these individuals (Authors; Kaur et al. 2018; Shumway et al. 2019). Caregivers often facilitate their children's care, and provide pragmatic and emotional support to their children, and therefore warrant attention as a population of study in their own right (Russell et al. 2020). This high level of care is challenging to maintain, as with any chronic, relapsing condition. In the case of SUDs, the challenges caregivers face may be exacerbated by the stigma and the blame associated with parents in the development and maintenance of children's SUDs, and the strains that come with navigating barriers related to accessing treatment in the USA.

The purpose of the present paper is to highlight the need for improvements in access to SUD treatment in the USA, particularly the inclusion of caregivers in systemic family therapy within SUD treatment for adults. We use the term systemic family therapy here to refer to a broad set of family therapy services that are united through their grounding in the use of General Systems Theory as a central organizing framework. We synthesize the extant literature on the role of family members in SUD treatment, as families are a primary context of care for their children's treatment across many chronic, relapsing conditions. We selected SUD research to review by searching the recent, extant literature from prominent peer-reviewed journals in the mental health, health, and substance use fields for treatment studies that included family members. Finally, we identify the importance of addressing family member's unique needs related to their loved one with a SUD, both in the family and in a treatment context. The authors establish this review as a foundation for future family-focused substance use treatment and intervention development.

\section{Background}

\section{Substance Use Disorders in the USA}

According to the United States National Institute on Drug Abuse, (NIDA) 948,000 Americans reported using heroin in 2016 (NIDA 2018). Heroin and opioid use carry devastating immediate and chronic health impacts and social issues which include respiratory complications, overall poor health, mental disorders, social isolation, secondary infections, economic instability, homelessness, poverty, and employment instability (NIDA 2018). The greatest increases in disordered opioid use are among adults between ages 18 and 25 both in urban and suburban areas across the USA (NIDA 2018). This widespread increase in use which transcends gender, culture, and location has prompted government officials to identify that the country is in an opioid crisis; this is the deadliest drug overdose crisis in the United States history. The opioid crisis was responsible for 42,000 deaths in 2016 (NIDA 2018), prompting the US Senate to develop The Opioid Crisis Response Act (OCRA) of 2018, which is projected to cost approximately 1.5 billion dollars between 2019-2021 (NIDA 2018). There is a demand for programming to address the recurrent nature of SUDs and their deleterious effects. 
Despite the prevalence of SUDs in the USA, many individuals remain untreated (Grant et al. 2016). The Substance Abuse and Mental Health Services Administration (SAMHSA 2017 ) estimates that approximately $11 \%$ of individuals in need of SUD treatment receive it. What is more concerning, nearly $30 \%$ of individuals report receiving treatment that is "minimally adequate" in scope and breadth (CBHSQ, 2016). This statistic indicates that clients seeking treatment report that the treatment received was not adequate in resolving the presenting problem. Estimates suggest that healthcare spending for substance use treatment is relatively low. Between 2009 and 2012, only $0.6 \%$ of individuals with private insurance used SUD outpatient services, $0.2 \%$ filled SUD medication prescriptions, and $0.1 \%$ used inpatient SUD services (Thomas et al. 2016). Taken together, it is clear that substance use treatment lags behind need both in terms of access and utilization, yet unanswered questions about how the patterns of inequity in healthcare writ large play out in young adults' SUD treatment remain.

\section{Disparities in Access to SUD Treatment in the United States}

Commercial and Social Insurance Status Disparities Among the un-insured and underinsured in the USA, financial barriers are the most common reason stated for not seeking treatment (Cheng and Robinson 2013). Stigma and lack of readiness to change were reported as barriers to treatment-seeking for individuals with insurance coverage (Ali et al. 2017). It seems clear that insurance coverage for mental health and substance abuse services is a critical consideration for treatment initiation and continuation. Having personal health insurance that provides coverage for SUD treatment is an important promotive factor in treatment-seeking (Cook and Alegría 2011; Lundgren et al. 2005; Pinedo 2019). Having specialty coverage (i.e., medication-assisted treatment or substance-specific treatment) as part of one's health insurance plan increases rates of treatment initiation for those services (Cummings et al. 2014). A critical consideration in insurance reimbursement is the distinction between supportive family involvement and family therapy.

Receipt of substance abuse treatment is generally the lowest among those that are uninsured or under-insured. National probability data (Mark et al. 2015) suggest that $4 \%$ of individuals with current Medicaid insurance have sought substance use treatment, and rates are even lower for uninsured individuals (3.4\% for uninsured individuals with incomes $139 \%$ of the federal poverty level (FPL); $2.8 \%$ for uninsured individuals with incomes between 133 and $399 \%$ of FPL). Others (Wu, Kouzis, \& Schlenger 2003) have suggested rates of substance use treatment service utilization are the lowest among the uninsured, with only about $1.6 \%$ of individuals initiating treatment for a SUD within the previous year. Data from the National Survey of Drug Use and Health, an annual, nationally representative, cross-sectional survey, indicates that not only are many individuals un-insured or under-insured, but many lack awareness of coverage for substance use or mental health treatment under their plan (Cummings et al. 2014). Data indicated that approximately $30 \%$ of individuals with a SUD were uninsured, and nearly half of individuals privately insured did not know whether their plan provided coverage for SUD treatment (Cummings et al. 2014). In communities with high proportions of uninsured residents, individuals of African American or Latin descent are less likely to have access to SUD treatment facilities regardless of insurance coverage (Cummings et al. 2014; Pinedo, 2019). There are racial/ethnic disparities SUD in treatment receipt and treatment and recovery outcomes. African Americans are more likely to access treatment (Mulvaney-Day, DeAngelo, Chen, Cook, \& Alegria 2012; SAMHSA 2016) while Latinos are less likely to access treatment than majority group members (Cook and Alegría 2011). 
Members of ethnic/racial minority groups are likely to experience delays in accessing treatment (Wells, Klap, Koike, \& Sherbourne 2001), and report lower rates of treatment completion (Guerrero, Campos, Urada, \& Yang 2012; Guerrero, Marsh, Duan, et al. 2013). African American individuals are more likely to utilize counseling approaches to treatment when their health insurance provides for such coverage (Cheng and Robinson 2013). These patterns of treatment use and non-use indicate that substance use treatment is not equally available to all individuals who may need to access it.

While the United States' Wellstone Act (The Mental Health Parity and Addiction Equity Act 2008) provides federally mandated coverage for mental health treatment, it does not provide uniform coverage for supportive family experiences, such as family meetings, family weekends, and social or psychoeducational groups, common mechanisms of family involvement in substance use treatment. The Act provides mental health parity, which includes therapeutic family contact, both with and without the substance using individual. Insurance reimbursement of services is both a barrier and promotive factor to substance use treatmentseeking (Cummings et al. 2014) and must be considered part of a broader investigation of socioeconomic determinants of health.

Socioeconomic Status and Access to Care in the USA Medicaid is the largest source of public funding for SUD treatment in the USA (Mark et al. 2016). While having Medicaid or other federally supported health insurance coverage increases the likelihood of substance use treatment initiation (Bouchery et al. 2012), ethnic minorities are overrepresented in the Medicaid population (Kaiser Family Foundation 2017), and lack of providers who accept Medicaid as payment for services limits access to treatment, strengthening health disparities. Data from a national, longitudinal study (data from participants of the National Epidemiologic Survey on Alcohol and Related Conditions) indicates that compared to the uninsured, participants with Medicaid had higher odds of receiving SUD treatments that are potentially covered by health insurance, such as detoxification and rehabilitation services (Mojtabai et al. 2018). Furthermore, disparities existed in utilization rates for services typically covered by private health insurance such as outpatient, residential, and medication-assisted treatments (Mojtabi et al. 2018). While Medicaid coverage has expanded in recent years, these expansions have not been evenly distributed across the population, (Beronio et al. 2014; Peterson \& Busch 2018) and potentially exacerbate racial disparities in health care and substance use treatment (Andrews et al. 2015). Despite positive policy changes, particularly as it relates to adults without children, rates of substance use treatment service utilization did not increase accordingly, and treatment utilization rates remain low, particularly for lower-income individuals and ethnic minority group members (Saloner et al. 2017). Services such as outpatient treatment, residential services, and medication-assisted treatment have the strongest evidence base (Glasner-Edwards \& Rawson 2010) and ought to be made more accessible to individuals in need of substance use treatment. These data suggest that un-insured and under-insured low-income individuals and families have just as great a need for substance use services and mental health services, if not greater, than their adequately insured counterparts.

Taken together, it is clear that socioeconomic status, insurance coverage, and other social determinants of health include race/ethnicity, impact substance use treatment provision, and individual engagement and outcomes. Family caregivers, most frequently parents, often facilitate their children's health care, particularly when facing chronic relapsing diagnoses, and provide pragmatic and emotional support to their children throughout the treatment process (Kaur et al. 2018; Russell and Guite In Press). Providing this high level of support and care is challenging to maintain, particularly for families navigating stigma and other barriers to treatment engagement. 


\section{Families as the Context of Care for Substance Use Disorders}

In addition to the deleterious individual impacts of SUDs, family members of the substance using person (including parents, partners, caregivers, and children) also experience serious impacts (Rowe 2012). Substance use disorders are conceptualized as the result of multiple factors including the individual, the family, the peer and social group, and the community system (Rowe 2012). Factors that impact family functioning include parental psychopathology, family conflict, relational distance, and parenting skills each of which is a strong predictor of drug use initiation and chronic drug abuse (Tobler and Komro 2010; Rowe 2012). Conversely, supportive parenting offers a significant protective factor that serves to reduce substance use over time (Brody et al. 2009; Rowe 2012). Decades of research findings support the reciprocal relationship between family functioning and substance use (Fals-Stewart et al. 2009; Rowe 2012). For example, high levels of relationship dysfunction and conflict, and low family support may contribute to substance use among adults, while substance use of a family member can also contribute to such family dysfunction (Fals-Stewart et al. 2009). These findings illustrate that family relationships are a key factor in the development and maintenance of SUDs.

Families serve as the primary context of care for most chronic, relapsing conditions. "Intervention strategies that support parents, who are both the gatekeepers for their child's healthcare access and partners in providing ongoing support for their child, are proving to be an important consideration" across treatment settings (Russell et al. 2020, p.10). Substance use disorders affect the entire family system and have been conceptualized as a family disease (Lander et al. 2013; McPherson et al. 2017; Brown and Lewis 1995; Roth 2010). When one family member has a SUD, family members may change their behavior to keep their loved one safe and healthy, and changes to the family system may remain after the SUD member achieves sobriety (Wegscheider-Cruse and Cruse 2012; Shumway et al. 2019). Research involving the specific ways family members are influenced by SUDs is limited, but some research indicates that family members experience co-suffering, or co-impairment (Shumway et al. 2019) and intense physical, emotional, and relational distress (Author) related to a family member's SUD.

Caregiving Burden and SUDs When a young adult develops a SUD, a parent typically assumes a caregiving role and experiences burdens associated with this off-time life event and with the caregiving role (Author; Kaur et al. 2018). A primary aspect of caregiving may involve identifying treatment options, facilitating entrance to treatment programs, providing financial support for and during recovery, and supporting treatment engagement throughout the recovery process. Given the critical role that parents hold in the lives of young adults, including the emotional and financial ties, parents of substance using young adults warrant treatment in their own right (Russell and Guite In Press; Authors, In Review). Viable family interventions must address family members' individual needs, stressors, and role of the family system of the person with a SUD. For families with a child with a chronic, relapsing health condition like a SUD, the routines and relationships of the home are the context in which family members will develop skills to support the life-long process of recovery. For many families, the emotional and pragmatic/tangible supports of childrearing extend beyond the age of 18; many families continue to advise, support, and nurture their grown children's physical and psychological wellbeing throughout adulthood, heightening levels of care and involvement when need arises (Authors; Gavazzi and Sabatelli 1990). For young adults with SUDs, 
treatment and recovery occur during an already developmentally vulnerable time- when young adults are also learning who they are, in relation to and independent of their family of origin (Erikson 1968).

Family members occupy an essential role in SUD treatment, given the tangible and emotional support parents in particular can offer their young adult children (Ryan-Pettes et al. 2020). Research has identified financial strains associated with family member's SUDs (Orford et al. 2013) and with maternal caregiving for SUD young adults (Author, In Review). Parents of young adults diagnosed with SUDs are put in the position of coordinating care in an environment where resources, treatment, and payment options are scarce. This process involves substantial stress on the part of the parents, who experience physical and emotional distress as a result (D'Aniello et al. 2020; Shumway et al. 2019). Supporting children and families as they cope with chronic relapsing health conditions is a sharply felt need heightened by the critical impacts of the opioid epidemic and ongoing sometimes systematic barriers to accessing effective health care (Andrews et al. 2015; Kaur et al. 2018). An aspect of this problem that has received little research attention is the parent and family factors related to seeking treatment and service utilization. Additionally, there is scant literature that describes the degree to which parents understand their child's SUD and the process of recovery and the most adaptive ways to support positive outcomes as a caregiver.

Concurrent with coordinating care for a young adult child recovering from a SUD are the intertwined psychological and relational experiences of parent and child. Parents experience distress about their child's SUD including fear, anger, disappointment, frustration, sadness, and depression (Authors, In Review; Shumway et al. 2019). Furthermore, parents experience the impacts of their child's experience. Children's distress is an additional stressor for parents to cope with, illustrating the bidirectional nature of families. Parents' struggles with anger or depression impact their children, as children's struggles impact their parents, and so the management of distress becomes complex in family systems.

The effects of a SUD reach beyond the substance using person, to the family members in the using person's context. Bronfenbrenner's bioecological theory of human development (Bronfenbrenner and Evans 2001) explains that a developing individual is viewed as influencing, and being influenced by the environment (Tudge et al. 2009; Tudge 2013). The central aspect of the theory is the concept of proximal process, which Bronfenbrenner conceptualized as enduring forms of interaction in the immediate environment, occurring on a regular basis (Bronfenbrenner and Evans 2001). Thus, individuals not only do have personal experiences and their own coping strategies related to emotional distress and dysregulation but also participate in the mutual regulation of their family members' distress.

\section{The Distinction Between Family Therapy and Family-Involved Treatment}

The adaptation and adoption of family-based interventions to support mental health and substance use treatment are widely supported and considered a critical aspect of recovery (Rowe 2012). The consistent failure to successfully apply this knowledge to service settings (Fixen et al. 2009) is often based on the failure to adapt models of intervention to unique clinical settings. Given the compelling evidence supporting the link between the family environment and SUDs, treatment providers routinely include family members in substance use treatment (Gruber and Fleetwood 2004; Rowe 2012); however, these approaches have been met with limited success. In general, family approaches aim to (1) leverage the family 
member's support to reduce substance use frequency and (2) alter the problematic aspects of the family context to promote recovery (Fals-Stewart et al. 2009).

Family-Involved Treatment Models There is a critical distinction between family-involved SUD treatment and systemic family therapy including the substance using person and their immediate family members. Family involvement is increasingly common in SUD treatment. A pioneering study of family treatment for substance using adults (Stanton \& Todd 1982) clearly established the value of family treatment, and inspired decades of related research, including the emergence of some empirically supported treatments for SUDs. This involvement occurs in various formats, most commonly through a family day, or visitation opportunities at a treatment center. Family visitation is typically held on weekends to allow family members to travel to the recovery center, and a series of events and activities are offered that include individual meetings with the family and their recovering loved one, family psychoeducation, and/or multi-family groups. Family therapy, on the other hand, involves specific, focused treatment addressing family roles, relationships, boundaries, and functioning.

Two prominent examples of empirically supported models of family therapy are evident in the family therapy literature: Multidimensional Family Therapy and Multisystemic Family Therapy. For youth, Szapocznik and colleagues were the first to establish the effectiveness of family therapy in treating adolescent drug use (Szapocznik et al. 1983, 1986, 1988). Efforts to develop empirically supported treatment models to engage family members with a substance using youth or teen have grown out of this need. One such model, Multidimensional Family Therapy (Liddle 1992; Liddle and Dakof 1994), is an integrative, empirically supported treatment for adolescent drug abuse and associated behavior problems. Similarly, Multisystemic Family Therapy (MST; Henggeler et al. 1996) is another empirically supported treatment model that addresses adolescent drug use with youth living full time in parents' homes through in-home family treatment. The models are similar in that they are family-based and providers attempt to modify interaction and parenting behaviors within the family. Substantial literature has demonstrated the efficacy and efficaciousness of MDFT (c.f. Liddle et al. 2001) and MST (c.f. Curtis et al. 2004; Henggeler, et al., 2007) in reducing adolescent drug use, antisocial and delinquent behaviors, and negative family functioning. A prominent mechanism of change in MDFT is the resolution of parent-adolescent conflict, including conflict in session (Diamond and Liddle 1996). The centrality of the parent-adolescent relationship in this model (Hogue et al. 2006) is further indication that the parents of substance using individuals are critical in understanding and modifying substance use behaviors. Similarly, in MST, core interventions relate the "fit circle" (Henggeler, et al., 1996), which focuses on modifications to the family ecology to develop pro-social behaviors in youth. It is clear that both models are efficacious in using family therapy to reduce the deleterious impacts of adolescence substance abuse.

The effectiveness of family-based adolescent drug treatment compared to other approaches has been well documented (Henggeler et al. 1996; Liddle et al. 1995), yet research and development of family treatment approaches for adult substance use lags behind. The Community Reinforcement Approach and Family Training (CRAFT; Scruggs et al. n.d.) is one family-involved model of SUD treatment for adult substance users. CRAFT is an evidencebased approach rooted in motivational interviewing techniques intended to support family members or friends to motivate the substance using individual in their life to enter treatment. An assumption of the CRAFT model is that the family member will be a "positive and active force for change" and that needs to learn specific skills to help their family member. The 
CRAFT model differs from systemic family therapy in that it does not include family members' emotional responses, thoughts, and behaviors related to their loved one's substance use, only assumes the caring supportive other is motivated to help the substance using family member and serve in a supportive role. Research into the effectiveness of the CRAFT model on family functioning has resulted in inconsistent impact on parental stress level and family functioning (Manuel et al. 2012; Waldron et al. 2007; Roozen et al. 2010).

Taken together, it seems clear that family therapy is an effective and efficacious mechanism for reducing adolescent substance abuse and associated behavioral outcomes. Not only is family therapy for youth SUDs effective initially, results are maintained long term (Schaeffer and Borduin 2005). Adult SUD treatment that builds on these successes, however, lags behind in the integration of family in treatment. While CRAFT is a promising example of family-involved treatment, no model known to the authors represents systemic family therapy for young adults with SUDs.

Engaging family members, particularly caregivers, early in SUD treatment allows ample time for adjustment to the realities of a chronic condition. As with any chronic condition, the sooner treatment begins, the more likely it is that the individual and the family will develop healthful and functional relationship patterns. For example, through systemic family treatment, caregivers could learn to recognize behaviors consistent with SUDs as symptoms rather than simply, choices (e.g., lying/deception, denial, and relapse). Through family therapy, therapists can assist caregivers in identifying family interaction dynamics that may cue or trigger distress in the SUD family member, and learn to approach those interactions differently. Adapting family therapy approaches to be developmentally attuned with young adulthood and reflect the SUD treatment context is an important next step in strengthening treatment options for this population. For example, differentiation from the young adult's family of origin is a central developmental task for this age group (Kerr and Bowen 1988) and follows the normative experience during adolescence of increasing autonomy. Families often shift from a supervision and permission mindset to serving as a sounding board, building new roles that stress open communication through which the young adult explores ideas, tests possibilities for problem-solving, and seeks encouragement. The presence of a chronic relapsing health condition like SUDs can extend and complicate the individuation process with a return to roles that stress oversight, approval, and permission. Therapeutic approaches that support families to articulate mutually developed opportunities for autonomy and differentiation - as well as mutually agreed upon structures for supervision (house rules for shared living spaces and access to financial resources, for example) — would build on the successes of family therapy with adolescents in recovery to extend developmentally appropriate resources to families with young adults.

It is highly likely that family members themselves have developed maladaptive, symptomatic, often fear-based behavior in relationship to their SUD loved one (Shumway et al. 2019). Furthermore, it is also likely that these maladaptive, fear-based behaviors may continue after the using person finds recovery (Shumway et al. 2019). Therefore, every member of the family stands to benefit when caregivers find their own recovery from maladaptive relationship patterns that have developed around the SUD.

\section{Conclusion}

It is clear that SUDs in young adults present unique challenges and stressors to parents of these individuals (Authors; Kaur et al. 2018; Shumway et al. 2019) and disturbances to family 
functioning for those in recovery are common. When a young adult develops a SUD, a parent typically assumes a caregiving role and suffers an emotional, financial, and familial burden as a result (Authors; Kaur et al. 2018); thus, families serve as the primary context of care for SUDs as they do for most chronic, relapsing conditions. Myriad research findings demonstrate the reciprocal relationship between family functioning and substance use (Fals-Stewart et al. 2009; Rowe 2012) such that supportive parenting positively impacts substance use and associated behaviors (Brody et al. 2009; Rowe 2012). Also, this care comes at a steep personal cost: stigma associated with SUDs also impacts families and caregivers (Authors) in detrimental ways, for example, caregivers who perceive stigma may avoid, delay, or otherwise disengage from identifying and supporting treatment engagement for their diagnosed child. Systemic family therapy is an ideal treatment context to address these issues

In the case of youth substance use and associated behaviors, family therapy models have not only evolved, but have become the gold standard in care, demonstrating positive outcomes and superiority over individually-oriented or family-involved models (Henggeler et al. 1996; Liddle et al., 1995). Furthermore, there is substantial support in terms of service reimbursement by insurance providers for family therapy, as opposed to supportive, family-involved, events and practices that are not covered through the Wellstone Act. It is long past time for providers, payers, and stakeholders in young adults' SUD treatment to approach family therapy interventions - and other caregiver burden interventions in their own right — as viable interventions to resolve substance use and the family factors that contribute to its maintenance.

\section{Compliance with Ethical Standards}

Conflict of Interest Rachel Tambling, Beth Russell, and Carissa D'Aniello declare that they have no conflict of interest.

Human and Animal Rights No human subjects data were used in the present manuscript.

\section{References}

Ali, M. M., Teich, J. L., \& Mutter, R. (2017). Reasons for not seeking substance use disorder treatment: variations by health insurance coverage Springer. https://doi.org/10.1007/s11414-016-9538-3.

Andrews, C. M., Guerrero, E. G., Wooten, N. R., \& Lengnick-Hall, R. (2015). The medicaid expansion gap and racial and ethnic minorities with substance use disorders. American Journal of Public Health, 105, S452S454 Retrieved from https://ezproxy.lib.uconn.edu/login?url=https://search.ebscohost.com/login.aspx? direct=true $\& d b=$ psyh \&AN=2015-25455-026\&site=ehost-live. Accessed 12 Dec 2020

Beronio, K., Glied, S., \& Frank, R. (2014). How the affordable care act and mental health parity and addiction equity act greatly expand coverage of behavioral health care. The Journal of Behavioral Health Services \& Research, 41(4), 410-428. https://doi.org/10.1007/s11414-014-9412-0.

Bouchery, E. E., Harwood, H. J., Dilonardo, J., \& Vandivort-Warren, R. (2012). Type of health insurance and the substance abuse treatment gap. Journal of Substance Abuse Treatment, 42(3), 289-300. https://doi.org/10. 1016/j.jsat.2011.09.002.

Brody, G. H., Beach, S. R., Philibert, R. A., Chen, Y., Murry, V. M., \& Brown, A. C. (2009). Parenting moderates a genetic vulnerability factor in longitudinal increases in youths' substance use. Journal of Consulting and Clinical Psychology, 77(1), 1-11.

Bronfenbrenner, U., \& Evans, G. W. (2001). Developmental science in the 21st century: emerging questions, theoretical models, research designs and empirical findings. Social Development, 9(1), 115-125. https://oi. org/10.1111/1467-9507.00114. 
Brown, S., \& Lewis, V. M. (1995). The alcoholic family: a developmental model of recovery. San Francisco: Josey Bass.

Cheng, T. C., \& Robinson, M. A. (2013). Factors leading african americans and black caribbeans to use social work services for treating mental and substance use disorders. Health \& Social Work, 38(2), 99-109. https:// doi.org/10.1093/hsw/hlt005.

Cook, B. L., \& Alegría, M. (2011). Racial-ethnic disparities in substance abuse treatment: the role of criminal history and socioeconomic status. Psychiatric Services (Washington, D.C.), 62(11), 1273-1281. https://doi. org/10.1176/ps.62.11.pss6211_1273.

Cummings, J. R., Wen, H., Ritvo, A., \& Druss, B. G. (2014). Health insurance coverage and the receipt of specialty treatment for substance use disorders among US adults. Psychiatric Services, 65(8), 1070-1073. https://doi.org/10.1176/appi.ps.201300443.

Curtis, N. M., Ronan, K. R., \& Borduin, C. M. (2004). Multisystemic treatment: a meta-analysis of outcome studies. Journal of Family Psychology, 18(3), 411-419.

D’Aniello, C., Tambling, R., Russell, B., Smith, M., Jones, E., \& Silva, M. (In press). Mothers' experiences of navigating the sud treatment system with their young adult child. American Journal of Family Therapy. (In Press).

Diamond, G., \& Liddle, H. A. (1996). Resolving a therapeutic impasse between parents and adolescent in multidimensional family therapy. Journal of Consulting and Clinical Psychology, 64(3), 481-488.

Erikson, E. H. (1968). Identity: Youth and crisis. New York: W. W. Norton \& Company.

Fals-Stewart, W., Lam, W., \& Kelley, M. L. (2009). Learning sobriety together: Behavioural couples therapy for alcoholism and drug abuse. Journal of Family Therapy, 31, 115-125. https://doi.org/10.1111/j.1467-6427. 2009.00458.x.

Fixen, D. L., Blase, K., Naoom, S., \& Wallace, F. (2009). Core implementation components. Research on Social Work Practice, 19(5), 531-540. https://doi.org/10.1177/1049731509335549.

Gavazzi, S. M., \& Sabatelli, R. M. (1990). Family systems dynamics, the individuation process, and psychosocial development. Journal of Adolescent Research, 5, 500-519.

Glasner-Edwards, S., \& Rawson, R. (2010). Evidence-based practices in addiction treatment: Review and recommendations for public policy. Health Policy, 97(2-3), 93-104. https://doi.org/10.1016/j.healthpol. 2010.05.013.

Gorman-Smith, D., Tolan, P. H., \& Henry, D. B. (2000). A developmental-ecological model of the relation of family functioning to patterns of delinquency. Journal of Quantitative Criminology, 16, 169-198.

Grant, B. F., Saha, T. D., Ruan, W. J., Goldstein, R. B., Chou, S. P., Jung, J., Zhang, H., Smith, S. M., Pickering, R. P., Huang, B., \& Hasin, D. S. (2016). Epidemiology of DSM-5 drug use disorder: Results from the National Epidemiologic Survey on Alcohol and Related Conditions-III. JAMA Psychiatry, 73(1), 39-45. https://doi.org/10.1001/jamapsychiatry.2015.2132.

Gruber, K. J., \& Fleetwood, T. W. (2004). In-home continuing care services for substance use affected families. Substance Use and Misuse, 39(9), 1379-1403. https://doi.org/10.1081/ja-120039395.

Guerrero, E. G., Campos, M., Urada, D., \& Yang, J. C. (2012). Do cultural and linguistic competence matter in Latinos' completion of mandated substance abuse treatment? Substance Abuse Treatment, Prevention, and Policy, 7. https://doi.org/10.1186/1747-597X-7-34.

Henggeler, S., Pickrel, S., Brondino, M., \& Crouch, J. (1996). Eliminating (almost) treatment dropout of substance abusing or dependent delinquents through home-based multisystemic therapy. The American Journal of Psychiatry, 153, 427-430.

Hogue, A., Dauber, S., Samuolis, J., \& Liddle, H. A. (2006). Treatment techniques and outcomes in multidimensional family therapy for adolescent behavior problems. Journal of Family Psychology, 20(4), 535-543.

Kaiser Family Foundation. (2020, -10-23T20:13:51+00:00). Distribution of the Nonelderly with Medicaid by Race/Ethnicity. https://www.kff.org/medicaid/state-indicator/medicaid-distribution-nonelderly-byraceethnicity/.

Kaur, A., Mahajan, S., Deepti, S. S., \& Singh, T. (2018). Assessment of role of burden in caregivers of substance abusers: a study done at Swami Vivekananda Drug De-addiction Centre, Govt. Medical College, Amritsar. International Journal of Community Medicine and Public Health, 5(6), 2380-2383. https://doi.org/10. 18203/2394-6040.ijcmph20182162.

Kerr, M., \& Bowen, M. (1988). The role of the family as an emotional unit that governs individual behavior and development: family evolution. Ontario: Penguin Books Ltd..

Lander, L., Howsare, J., \& Byrne, M. (2013). The impact of substance use disorders on families and children: from theory to practice. Social Work in Public Health, 28(3-4), 194-205. https://doi.org/10.1080/19371918. 2013.759005 .

Liddle, H. A. (1992). Family therapy techniques for adolescents with drug and alcohol problems. In W. Snyder \& T. Ooms (Eds.), Empowering Families: ADAMHA Monograph from the First National Conference on the 
Treatment of Adolescent Drug, Alcohol, and Mental Health Problems. Washington, DC: U.S. Government Printing Office.

Liddle, H. A., \& Dakof, G. A. (1994). Efficacy of family therapy for drug abuse: promising but not definitive. Journal of Marital and Family Therapy, 21(4), 511-543. https://doi.org/10.1111/j.1752-0606.1995.tb00177. $\mathrm{X}$.

Liddle, H. A., Dakof, G. A., Parker, K., Diamond, G. S., Barrett, K., \& Tejeda, M. (2001). Multidimiensional family therapy for adolescent drug abuse: Results of a randomized clinical trial. American Journal of Drug \& Alcohol Abuse, 27(4), 651.

Lundgren, L. M., Amaro, H., \& Ben-Ami, L. (2005). Factors associated with drug treatment entry patterns among Hispanic women injection drug users seeking treatment. Journal of Social Work Practice in the Addictions, 5(1-2), 157-174. https://doi.org/10.1300/j160v5n01_08.

Manuel, J. K., Austin, J. L., Miller, W. R., McCrady, B. S., Tonigan, J. S., Meyers, R. J., Smith, J. E., \& Bogenschutz, M. P. (2012). Community reinforcement and family training: a pilot comparison of group and self-directed delivery. Journal of Substance Abuse Treatment, 43(1), 129-136. https://doi.org/10.1016/j.jsat. 2011.10.020.

Mark, T. L., Lubran, R., McCance-Katz, E., Chalk, M., \& Richardson, J. (2015). Medicaid coverage of medications to treat alcohol and opioid dependence. Journal of Substance Abuse Treatment, 55, 1-5. https://doi.org/10.1016/j.jsat.2015.04.009.

McPherson, C., Boyne, H., \& Willis, R. (2017). The role of family in residential treatment patient retention. International Journal of Mental Health and Addiction, 15(4), 933-941. https://doi.org/10.1007/s11469-0169712-0.

Mojtabai, R., Mauro, C., Wall, M. M., Barry, C. L., \& Olfson, M. (2020). Private health insurance coverage of drug use disorder treatment: 2005-2018. Plos One, 15(10), e0240298. https://doi.org/10.1371/journal.pone. 0240298

Mulvaney-Day, N., DeAngelo, D., Chen, C., Cook, B. L., \& Alegría, M. (2012). Unmet need for treatment for substance use disorders across race and ethnicity. Drug and Alcohol Dependence, 125, S44-S50. https://doi. org/10.1016/j.drugalcdep.2012.05.005.

NIDA. (2018). Heroin. Retrieved from https://www.drugabuse.gov/publications/research-reports/heroin on 2018, December 5 .

Orford, J., Velleman, R., Natera, G., Templeton, L., \& Copello, A. (2013). Addiction in the family is a major but neglected contributor to the global burden of adult ill-health. Social Science \& Medicine, 78, 70-77. https:// doi.org/10.1016/j.socscimed.2012.11.036 Epub 2012 Dec 8.

Peterson, E., \& Busch, S. (2018). Achieving mental health and substance use disorder treatment parity: A quarter century of policy making and research. Annual Review of Public Health, 39, 421-435. https://doi.org/10. 1146/annurev-publhealth-040617-013603.

Pinedo, M. (2019). A current re-examination of racial/ethnic disparities in the use of substance abuse treatment: Do disparities persist? Drug and Alcohol Dependence, 202, 162-167. https://doi.org/10.1016/j.drugalcdep. 2019.05.017.

Roozen, H. G., De Waart, R., \& Van Der Kroft, P. (2010). Community reinforcement and family training: an effective option to engage treatment-resistant substance-abusing individuals in treatment. Addiction, 105(10), 1729-1738. https://doi.org/10.1111/j.1360-0443.2010.03016.x.

Roth, J. D. (2010). Addiction as a family disease. Journal of Groups in Addiction \& Recovery, 5, 1-3. https://doi. org/10.1080/15560350903547189.

Rowe, C. L. (2012). Family therapy for drug abuse: review and updates 2003-2010. Journal of Marital and Family Therapy, 38(1), 59-81. https://doi.org/10.1111/j.1752-0606.2011.00280.x.

Russell, B.S. \& Guite, J.W. (In Press). Parenting impacts from a mindfulness-based pilot intervention for families facing pediatric chronic pain. Journal of Child and Family Studies.

Russell, B. S., Guite, J. W., Homan, K., Teppe, R., \& Williams, S. (2020). Complementary parent components for pediatric pain families: Innovations in treatment. Children, 7, 4. https://doi.org/10.3390/ children7010004.

Ryan-Pettes, S. R., Devoto, A., \& DeFulio, A. (2020). Acceptability and willingness to pay for contingency management interventions among parents of young adults with problematic opioid use. Drug and Alcohol Dependence, 206, 107687.

Saloner, B., Bandara, S., Bachhuber, M., \& Barry, C. L. (2017). Insurance coverage and treatment use under the affordable care act among adults with mental and substance use disorders. Psychiatric Services, 68(6), 542548. https://doi.org/10.1176/appi.ps.201600182.

Schaeffer, C. M., \& Borduin, C. M. (2005). Long-term follow-up to a randomized clinical trial of multisystemic therapy with serious and violent juvenile offenders. Journal of Consulting and Clinical Psychology, 73(3), $445-453$. 
Scruggs, S., Meyer, R., \& Kayo, R. (n.d.). Community reinforcement and family training support and prevention. Retrieved November 12, 2015, from http://www.mirecc.va.gov/visn16/docs/CRAFT-SP_Final.pdf. Accessed 12 Dec 2020

Shumway, S. T., Bradshaw, S. D., Hayes, N., Schonian, S., \& Kimball, T. G. (2019). Prefrontal cortex functioning of family members of those with substance use disorders. Alcoholism Treatment Quarterly, 37(1), 75-98. https://doi.org/10.1080/07347324.2018.1488549.

Smokowski, P., Corona, R., Bacallao, M., Fortson, B. L., Marshall, K. J., \& Yaros, A. (2018). Addressing barriers to recruitment and retention in the implementation of parenting programs: lessons learned for effective program delivery in rural and urban areas. Journal of Child and Family Studies, 27(9), 29252942. https://doi.org/10.1007/s10826-018-1139-8.

Stanton, M. D., \& Todd, T. C. (1982). The Family Therapy ofDrug Abuse and Addiction. New York: Guilford Press.

Substance Abuse and Mental Health Services Administration, Center for Behavioral Health Statistics and Quality. (2017). Results from the 2016 national survey on drug use and health: detailed tables. Retrieved from https://www.samhsa.gov/data/sites/default/files/NSDUH-DetTabs-2016/NSDUH-DetTabs-2016.htm\# tab9. Accessed 12 Dec 2020

Szapocznik, J., Kurtines, W. M., Foote, F. H., Perez-Vidal, A., \& Hervis, O. (1983). Conjoint versus one-person family therapy: some evidence for the effectiveness of conducting family therapy through one person. Journal of Consulting and Clinical Psychology, 51(88), 1-899.

Szapocznik, J., Kurtines, W. M., Foote, F. H., Perez-Vidal, A., \& Hervis, O. (1986). Conjoint versus one-person family therapy: further evidence for the effectiveness of conducting family therapy through one person with drug-abusing adolescents. Journal of Consulting and Clinical Psychology, 54, 395-397.

Szapocznik, J., Perez-Vidal, A., Brickman, A. L., Foote, F. H., Santisteban, D., Hervis, O., \& Kurtines, W. (1988). Engaging adolescent drug abusers and their families in treatment: a strategic structural systems approach. Journal of Consulting and Clinical Psychology, 56, 552-557.

The Mental Health Parity and Addiction Equity Act, Public law: Pub.L. 104-204 (2008).

Thomas, C. P., Hodgkin, D., Levit, K., \& Mark, T. L. (2016). Growth in spending on substance use disorder treatment services for the privately insured population. Drug and Alcohol Dependence, 160, 143-150. https://doi.org/10.1016/j.drugalcdep.2015.12.024.

Tobler, A. L., \& Komro, K. A. (2010). Trajectories of parental monitoring and communication and effects on drug use among urban young adolescents. The Journal of Adolescent Health, 46(6), 560-568.

Tudge, J. R. H. (2013). Urie Bronfenbrenner. In H. Montgomery (Ed.), Oxford bibliographies on line: Childhood studies. New York: Oxford University Press. https://doi.org/10.1093/OBO/9780199791231-0112.

Tudge, J. R. H., Mokrova, I., Hatfield, B., \& Karnik, R. B. (2009). Uses and misuses of Bronfenbrenner's bioecological theory of human development. Journal of Family Theory \& Review, 1, 198-210. https://oi. org/10.1111/j.1756-2589.2009.00026.x.

Waldron, H. B., Kern-Jones, S., Turner, C. W., Peterson, T. R., \& Ozechowski, T. J. (2007). Engaging resistant adolescents in drug abuse treatment. Journal of Substance Abuse Treatment, 32(2), 133-142. https://doi.org/ 10.1016/j.jsat.2006.07.007.

Wegscheider-Cruse, S., \& Cruse, J. (2012). Understanding codependency: the science behind it and how to break the cycle. Deerfield Beach: Health Communications, Inc..

Wells, K., Klap, R., Koike, A., \& Sherbourne, C. (2001). Ethnic disparities in unmet need for alcoholism, drug abuse, and mental health care. The American Journal of Psychiatry, 158(12), 2027-2032. https://doi.org/10. 1176/appi.ajp.158.12.2027.

Wu, L., Kouzis, A. C., \& Schlenger, W. E. (2003). Substance Use, Dependence, and Service Utilization Among the US Uninsured Nonelderly Population. American Public Health Assn. https://doi.org/10.2105/AJPH.93. 12.2079.

Publisher's Note Springer Nature remains neutral with regard to jurisdictional claims in published maps and institutional affiliations. 